Article

\title{
Comparative Research of Microstructure and Mechanical Prop- erties of Stainless-Structural Steel Dissimilar Welds
}

\author{
Saulius Baskutis ${ }^{1}$, Jolanta Baskutiene ${ }^{1}$, Regita Bendikiene ${ }^{1, *}$, Antanas Ciuplys ${ }^{1}$ and Karolis Dutkus ${ }^{2}$ \\ 1 Department of Production Engineering, Faculty of Mechanical Engineering and Design, Kaunas University \\ of Technology, Studentu str. 56, LT-51424, Kaunas, Lithuania; saulius.baskutis@ktu.lt (S.B.); \\ jolanta.baskutiene@ktu.lt (J.B.); antanas.ciuplys@ktu.lt (A.C.) \\ 2 Umega Group AB, Kauno str. 120, LT-20115, Ukmerge, Lithuania; karolis.dutkus@hennordic.com \\ * Correspondence: regita.bendikiene@ktu.lt; Tel.: +370-685-96769
}

\begin{abstract}
The present study utilizes a metal inert gas welding (MIG) to make a dissimilar weld joint of different stainless steel grades AISI 304, 314, 316L, 420 and a standard structural steel S355MC to estimate the correlation of a microstructure and the mechanical properties. The microstructure of the base metals (BM), the heat affected zone (HAZ), the fusion zone (FZ) and the weld seam were analyzed using optical microscopy. Optical microscopy did not reveal any presence of weld defects such as porosity or cracks. The analysis of microstructure showed that both the austenitic and martensitic stainless steel weld structures contain some retained delta ferrite and coarse $\mathrm{Me}_{23} \mathrm{C}_{6}$ carbides in the HAZ, while the FZ exhibits delta ferrite and some retained austenite. The hardness profiles revealed difference between austenitic and martensitic steel welds that the later showed extremely high values in the HAZ ( 500 HV/0.1) which causes fracture in this zone. The welds of all austenitic steel grades withstood tensile test, showing the average tensile strength of $472 \mathrm{MPa}$ with fracture observed in the base metal zone. It made clear that the use of a filler rod 308LSI is suitable only for the austenitic stainless and structural steel dissimilar welds, and not appropriate for martensiticstructural steel welds. The achieved results revealed that the higher hardness of the martensitic phase in the HAZ of AISI 420 is closely related with the formation of untempered coarse martensitic structure and higher carbon content.
\end{abstract}

Keywords: stainless steel; metal inert gas welding; dissimilar welds; microstructure; mechanical properties

\section{Introduction}

Generation of hybrid structures of materials provides huge opportunities for constructors in creating and developing new products with the required properties and high reliability. Requirements related to the welding procedure of dissimilar steel welds cover the production of boilers, tanks, heat exchangers, pressure vessels used in various industries. Such a specific application requires different materials to be joined with high reliability and joint quality. However, due to the different complexity of materials, dissimilar welds may lead to unanticipated failures. The problems most commonly encountered in dissimilar weld joints are related to the formation of brittle phases and undesirable residual stress distribution across different zones of welds which initiates formation of cracks or failures of the joint before the expected service life [1,2]. Majority of these negative consequences can be solved in principle by adjusting the microstructure while welding. In order to get a higher quality weld and to avoid defects in dissimilar welds, proper selection of welding metals, filler material (if used) and welding parameters are needed. Usage of filler ensures better control of the corrosion resistance and mechanical properties of weld [3]. Important factors influencing strength of dissimilar metal weld are melting temperatures, thermal conductivity, coefficient of thermal expansion, dilution of metals in weld area, carbon migration from the steel having the higher carbon content toward lower carbon content steel [4]. In the welded joints with a similar base metals the crack formation 
may be prevented by a subsequent post weld heat treatment (PWHT) [5]. Unfortunately, the heat affected zone (HAZ) of austenitic stainless steels remains unaffected even after PWHT, meanwhile the PWHT has a huge impact on the mechanical properties, a formation of the HAZ microstructure and a fusion zone (FZ) of carbon and martensitic alloyed steels [6]. The correlation of the fatigue strength, tensile properties, hardness, and microstructure, of austenitic stainless and medium carbon steel dissimilar welds was reported [7] showing $40 \%$ lower fatigue strength of dissimilar welds compared to austenitic steel welds, and $30 \%$ lower when compared to medium carbon steel welds. Due to the fact that steels of the dissimilar welds possess different chemical composition, the major problem of microstructure heterogeneity arises [8]. This difference in the microstructure is a consequence of the formation of cracks not far from the fusion line that is an undesirable factor, which increases the inner stress concentration in the adjacent HAZ. Free carbon movement in the dissimilar welds of 304 stainless and carbon steel [9] also influences crack formation. It was observed that because of small cracks, the weakest area between welds of dissimilar metals forms close to the fusion line or along the martensitic transition adjacent to the fusion line [10]. This phenomenon is caused by hydrogen absorbed during welding. The strength properties of dissimilar welded stainless and low alloyed carbon steel are influenced by the diffusion of the base and weld metals, those having different coefficients of thermal expansion, which results the different residual stresses across the various zones of weldments [11].

Martensitic stainless steels grades are used instead of austenitic ones when high strength and hardness easier achievable by heat treatment rather than by the cold working, and when mechanical properties are more important than corrosion resistance. Welding of martensitic stainless steels may cause problems with increased hardness in the HAZ and the formation of martensitic structure with retained delta ferrite in it [1,12]. As it has been reported [12], the hardness of HAZ depends on tempering temperature, and, influenced by production of more martensite to ferrite and carbide $\mathrm{Me}_{23} \mathrm{C}_{6}$ transformation, decreases. The precipitation of $\mathrm{Me}_{23} \mathrm{C}_{6}$ carbide has a negative impact on both the mechanical properties and corrosion resistance of stainless steel AISI 420 weld. It was reported [13] that the increase in corrosion potential are greatly associated with higher $\mathrm{Cr}$ content.

There are numerous studies on the mechanical properties investigation in similar welds of steels, however there is limited information about mechanical properties/microstructure relation and comparison of dissimilar low carbon and martensitic and austenitic stainless steels welds.

This research was accomplished to evaluate influence of the peculiarities of the microstructure on a tensile behavior and hardness of MIG welded dissimilar joints. The comparative evaluation was done in terms of the microstructure, hardness tests, and tensile test behavior. Moreover, some of the achieved results were given as the guide to the welding practice of different grades of stainless and structural high strength low alloy steels.

\section{Experimental procedure}

The materials to be welded were $4 \mathrm{~mm}$ thickness sheets of austenitic stainless steels' grades AISI 304, 314, 316L, martensitic stainless steel AISI 420, and structural high strength low alloy steel S355MC. The martensitic stainless steel AISI 420 has relatively high hardness and high carbon content, whereas austenitic steels have lower carbon but higher chromium (up to $28 \%$ ) content, consequently the higher corrosion resistance. The details on the chemical composition and standardized mechanical properties of the steels under the research are presented in Table 1 and Table 2 respectively.

Table 1. Chemical composition of welded sheets.

\begin{tabular}{llllllllllll}
\hline \multirow{3}{*}{ Grade } & \multicolumn{10}{c}{ Chemical composition [\%] } \\
\cline { 2 - 10 } & $\mathrm{C}$ & $\mathrm{Mn}$ & $\mathrm{Si}$ & $\mathrm{P}$ & $\mathrm{S}$ & $\mathrm{Cr}$ & $\mathrm{Ni}$ & $\mathrm{Cu}$ & $\mathrm{N}$ & $\mathrm{Mo}$ \\
\hline
\end{tabular}




\begin{tabular}{lllllllllll}
\hline AISI 304 & 0.027 & 1.780 & 0.320 & 0.030 & 0.0010 & 18.05 & 8.05 & - & 0.660 & - \\
\hline AISI 314 & 0.056 & 1.520 & 1.810 & 0.022 & 0.0010 & 24.19 & 19.06 & 0.180 & 0.051 & - \\
\hline AISI 316L & 0.020 & 1.210 & 0.570 & 0.031 & 0.0010 & 16.80 & 10.10 & - & - & 2.10 \\
\hline AISI 420 & 0.441 & 0.280 & 0.360 & 0.027 & 0.0013 & 13.68 & - & - & 0.040 & - \\
\hline S355MC & 0.049 & 0.789 & 0.012 & 0.015 & 0.0080 & - & - & - & - & - \\
\hline ER 308LSi & 0.017 & 1.890 & 0.740 & 0.017 & 0.0110 & 19.67 & 10.20 & 0.120 & 0.074 & 0.16 \\
\hline
\end{tabular}

Fe-balance;

* filler road.

Table 2. Mechanical properties of steels.

\begin{tabular}{|c|c|c|c|c|c|c|}
\hline \multirow[b]{2}{*}{ Grade } & \multicolumn{6}{|c|}{ Mechanical properties } \\
\hline & $\begin{array}{c}\text { Yield point } \\
R_{p(0.2)}[\mathrm{MPa}]\end{array}$ & $\begin{array}{l}\text { Yield point } \\
R_{p(1)}[\mathrm{MPa}]\end{array}$ & $\begin{array}{c}\text { Tensile strength } \\
\qquad \boldsymbol{R}_{m} \text { [MPa] }\end{array}$ & $\begin{array}{c}\text { Elongation } \\
{[\%]}\end{array}$ & $\begin{array}{c}\text { Young's } \\
\text { modulus [GPa] }\end{array}$ & $\begin{array}{c}\text { Hardness } \\
\text { [HV] }\end{array}$ \\
\hline AISI 304 & 288 & 333 & 609 & 59.3 & $190-203$ & 167 \\
\hline AISI 314 & 309 & 360 & 609 & 56 & 200 & 176 \\
\hline AISI 316L & 286 & 290 & 608 & 57.5 & $190-205$ & 163 \\
\hline AISI 420 & 345 & 345 & 636 & 26 & 200 & 180 \\
\hline S355MC & 392 & 392 & 452 & 41 & $190-210$ & $155-195$ \\
\hline ER 308LSi* & $\geq 320$ & & $\geq 510$ & $\geq 25$ & & 160 \\
\hline * filler road. & & & & & & \\
\hline
\end{tabular}

The welded sheets were prepared into the necessary dimensions as EN ISO 96921:2013 recommends for Single-V butt weld. The groove $\alpha$ with the angle of $60^{\circ}$ was utilized on milling machine. The sheet edge geometry is presented in Figure 1. A $2 \mathrm{~mm}$ gap between the edges of the sheets was maintained. Before welding all prepared samples (Figure 2) were polished and degreased with ethanol in order to remove any surface dirt's, oxides or dusts.

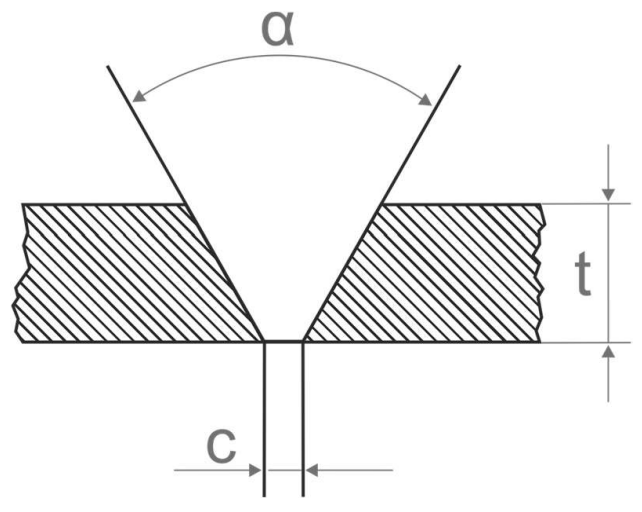

Figure 1. The geometry of sheet edge: $\alpha$ - an angle of the groove edge; $t$ - the thickness of the weldment; c-root opening. 


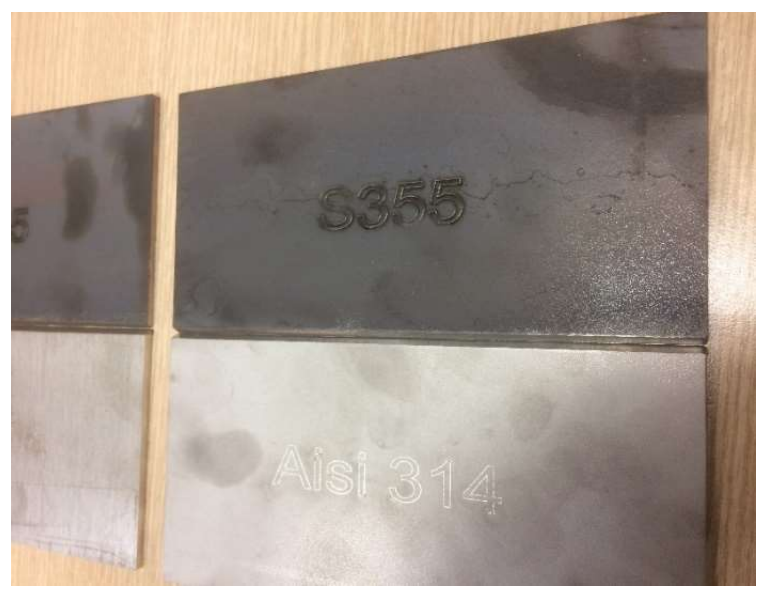

Figure 2. Grooved plates of different steels' grades prepared for welding.

Compact inverter welding machine Phoenix 355 Puls with integrated wire feed mechanism was utilized to compose welded joints. The samples were arranged precisely in the welding machine. Welding was carefully accomplished in one pass along the groove using Super-Pulse and Impulse welding techniques. The most suitable welding parameters have been chosen according to the weld seem quality, and are presented in Table 3.

Table 3. The main parameters of welding procedure.

\begin{tabular}{lccccc}
\hline $\begin{array}{c}\text { Welding } \\
\text { mode }\end{array}$ & $\begin{array}{c}\text { MIG current } \\
\text { [A] }\end{array}$ & $\begin{array}{c}\text { MIG voltage } \\
\text { [V] }\end{array}$ & $\begin{array}{c}\text { Wire feed } \\
\text { speed [m/s] }\end{array}$ & $\begin{array}{c}\text { Pulse duration during } \\
\text { welding [s] }\end{array}$ & $\begin{array}{c}\text { Heat input } \\
\text { [J/mm] }\end{array}$ \\
\hline $\begin{array}{l}\text { SuperPuls } \\
\text { (max) }\end{array}$ & 74 & 19.5 & 7.2 & $0.15(74 \mathrm{~A})$ & 230.88 \\
\hline $\begin{array}{l}\text { SuperPuls } \\
\text { (min) }\end{array}$ & 40 & 16.2 & 4.0 & $0.20(40 \mathrm{~A})$ & 103.68 \\
\hline $\begin{array}{l}\text { Impulse } \\
\text { Travel speed } 5.0 \mathrm{~mm} / \mathrm{s}\end{array}$ & 19.5 & 7.2 & - & 230.88 \\
\hline \begin{tabular}{l} 
Factor of thermal efficiency (MIG) 0.8 \\
\hline
\end{tabular}
\end{tabular}

A filler rod ER308LSi suitable for stainless steel MIG welding with a diameter of 0.8 mm was used (Table 1). This type of wire was chosen because of the minimum amount of carbon (the carbon content was held to a maximum of $0.02 \%$ ) in the composition that allows reducing the possibility of inter-granular carbide precipitation and ensuring good resistance to general corrosion. The composition of filler rod usually follows base metal composition, however, this is difficult to accomplish by welding different metals. Ni and $\mathrm{Mn}$ in the composition allows improving toughness and strength of the weld, but these elements also lower the temperature of martensitic transformation, which in turn increases the risk of retained austenite formation.

In order to prevent the liquid metal pool from the impact of environment, pure argon (99.9\%) was used as shielding gas (flow rate 20 1/min), which ensures a wide and shallow penetration of the weld bead, and enables to alter the length of the metal arc, not changing the heat of the arc. When welding is completed, all the weld samples were cleaned and cut at a direction perpendicular to weld into the test pieces for subsequent transverse tensile and hardness tests followed by the observation of microstructure. The cutting of the samples for tensile tests was done using Bystronic Bysprint $30154 \mathrm{~kW}$ fiber CNC laser cutting machine (Figure 3). 


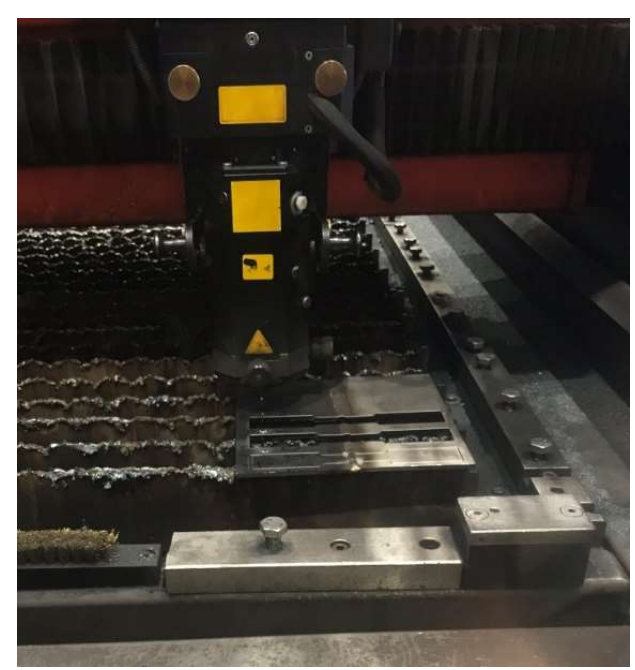

(a)

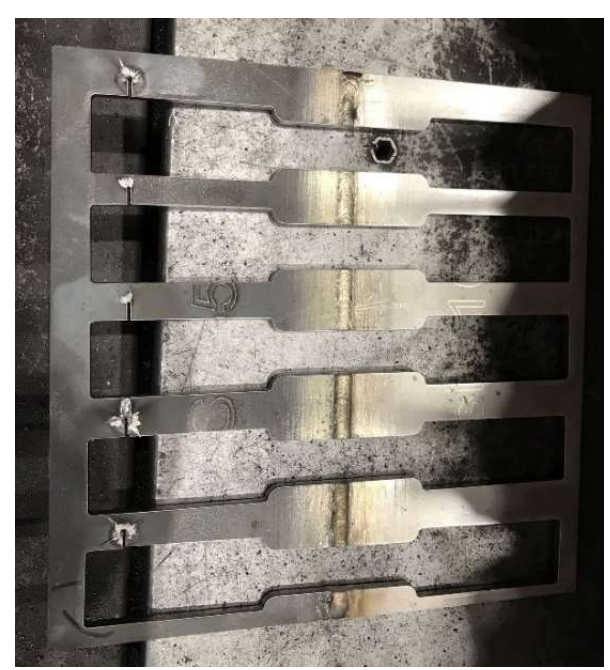

(b)

Figure 3. Laser cutting of the tensile samples: (a) Cutting process with CNC laser cutting machine; (b) Dissimilar weld samples after laser cutting.

The hardness test across the weld was executed using Mitutoyo Hardness Testing Machine HM-200 (Mitutoyo Corporation, Japan) using diamond indenter under the load of $0.98 \mathrm{~N}$ [14], with $10 \mathrm{~s}$ dwell time at $0.25 \mathrm{~mm}$ intervals $2 \mathrm{~mm}$ from the weld top surface while the original hardness of the base metal (BM) was reached (Figure 4).

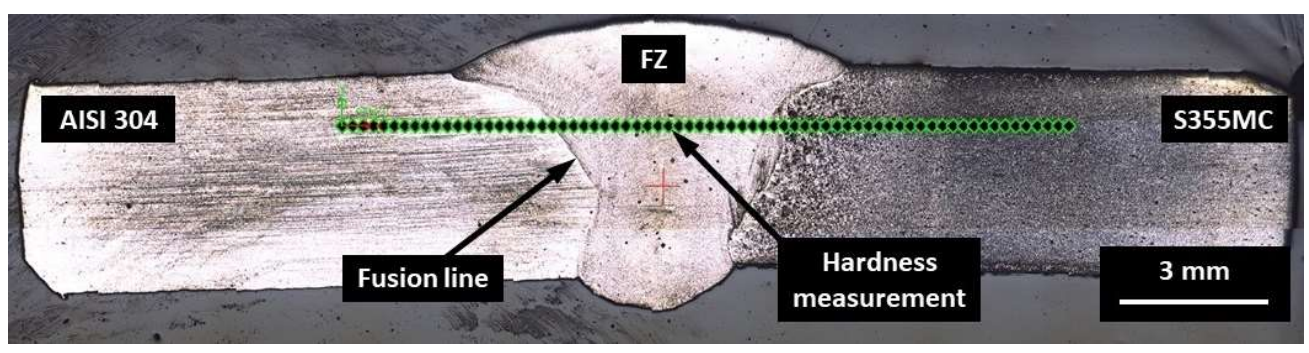

Figure 4. The cross section of the joint with the location of hardness test's indentations.

The transverse samples for optical analysis were prepared as required according to the basic procedures: grinding, the polishing to near a mirror finish, with following $30 \mathrm{~s}$ etching in Gliceregia etchant $(15 \mathrm{ml} \mathrm{HCl}, 10 \mathrm{ml}$ glycerol and $5 \mathrm{ml} \mathrm{HNO}$ ). In order to distinguish the different zones of the dissimilar welds as well as to gain data on grain distribution and size, the examination of optical micrographs was done using an optical microscope Carl ZeisAxio Scope A1. The hardness tests were performed at the ambient temperature of $20 \pm 2^{\circ} \mathrm{C}$ under the relative humidity of $50 \pm 5 \%$.

The tensile test pieces were subjected to a transverse tensile test to evaluate the strength of dissimilar weld and its exploitation properties [14]. The samples with gauge length of $60 \mathrm{~mm}$ were prepared according to the ISO 4136:2012 standard as presented in Figure 5. 


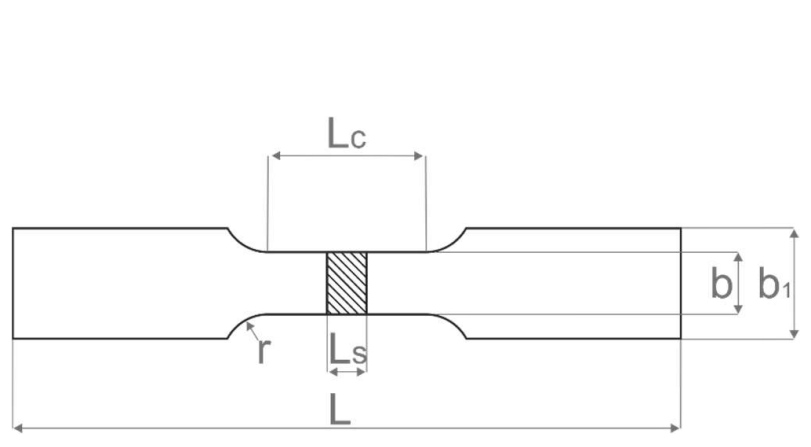

(a)

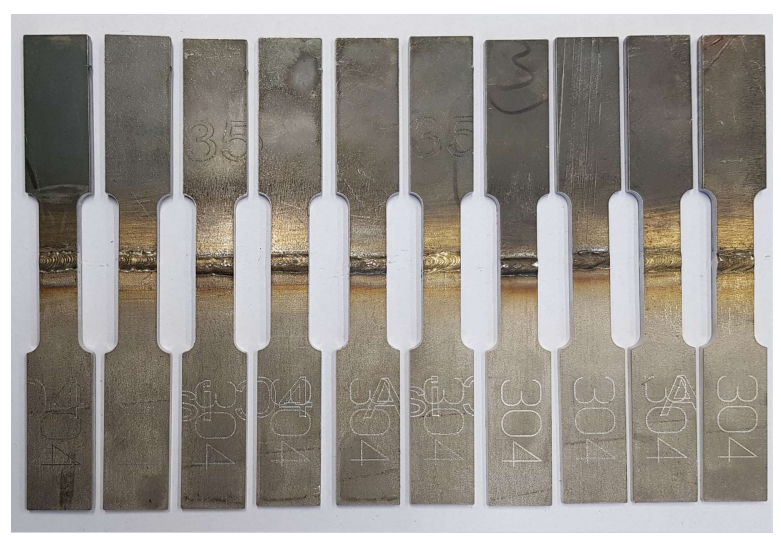

(b)

Figure 5. Tensile samples: (a) Tensile sample geometry: $L$ - total length; $L_{c}$ - gauge length; $L_{s}$ - thickness of sample; $b$ and $b_{1}$ - width; (b) Laser cut samples prepared for testing.

$50 \mathrm{kN}$ "Amsler" versatile electromechanical testing machine equipped with HBM testing device was used to accomplish the tensile tests at a crosshead speed of $2 \mathrm{~mm} / \mathrm{min}$ in the laboratory under the same conditions as the hardness tests.

\section{Results and discussion}

\subsection{The analysis of welds' microstructure}

The microstructure of different zones in dissimilar weld joints was studied, i.e. FZ (filler metal-depleted zone), partially melted zone (PMZ) (being observed close to the FZ, also known as dissolution zone), the HAZ usually found as the weakest part in the weldment, and the BM as area with no changes in the microstructure.

The optical micrographs of the weld cross-section of dissimilar joint of AISI 304, 314, 316L, 420 and structural steel S355MC are presented in Figures 6 and 7. During welding process due to the usage of filler metal with higher content of $\mathrm{Cr}$, which have a great affinity to carbon, some of the interstitial mobile carbon atoms migrates from the PMZ [15]. This relatively narrow carbon depleted zone is called decarburized region [16,17] or carbon-depleted zone [18-20] (Figure 6a). It has been observed that at relatively high levels of chromium (24.19\% in AISI 314), even small carbon content can cause the formation of chromium carbides $\mathrm{Me}_{23} \mathrm{C}_{6}$ at the grain boundaries of austenitic grains, especially on slow cooling (Figure 7d). Each single fine Me23C6 carbide starts to grow having a direct orientation to a matrix. Eventually $\mathrm{Me}_{23} \mathrm{C}_{6}$ precipitates forming a film-like coarse constituent, covering one adjacent grain side and forming a low $\mathrm{Cr}$ zone on the other adjacent grain side of the austenite grain boundary [21]. The presence of coarse $\mathrm{Me}_{23} \mathrm{C}_{6}$ carbides in a weldment has a negative effect on the mechanical properties. Therefore, during welding, apart from the appearance of carbide at the boundaries of austenitic grains, a local decrease of the content of chromium usually occurs because of short-term heating and slow cooling, which can cause steel affinity to an inter-granular corrosion. The increase of carbon content in the steel leads to the higher possibility chromium carbides to precipitate at the grain boundaries. The austenite phase in BM of stainless steels AISI 304 (Figure 6b), 314 (Figure 7d), 316L is embedded in the ferrite matrix with almost equal content of ferrite, while the microstructure of S355 MC steel consists of a mixture of perlite and acicular ferrite (Figure 6c) with typical fine-grained and interlocking structure [22]. The low carbon content $(0.049 \%)$ allows much more allotriomorphic ferrite to be formed with the grains that acquire equiaxed form due to the effect of hard impingement [23]. Allotriomorphic means that the form of the ferrite does not reflect its internal crystalline symmetry. This can be explained by the fact that it grows faster along the surface of austenitic grains. As 
a result of this process, its contours adjust the $\gamma$ grain boundaries. In the BM the amount of pearlite slightly reduces due to the lower carbon content in the steel.

The FZ can be described as a mixture of fully molten BM and filler metal with high degree of homogeneity where the mixing in the molten weld pool is primarily assured due to convection. As shown in the Figure $6 \mathrm{~d}$, the austenite based dendrites prevailed in the FZ. Additionally, optical micrographs of FZ (Figure 6d) showed the formed delta ferrite resulting from the ferrite-austenite solidification process. The highest delta ferrite content in the structure indicates that the weld is strong enough [24]. The increase in delta ferrite compared to the BM of AISI 304 was associated with relatively high temperature maintenance during solidification process. As an experimental research showed, formation of dendritic carbides did not induce any brittleness in the FZ and did not impair the strength properties of the weld seam.

The optical micrographs of dissimilar weld AISI 420/S355MC and microstructures across the HAZ from the FZ to AISI 420 BM are presented in Figure 7c and Figure 8, respectively. These elongated fine crystals and relatively large inter-crystalline zones are the evidence of the typical dendritic structure (Figure 8b). Compared with the BM, the increase in austenite content in the weld area can be explained by usage of filler road containing relatively high content of nickel $(10.2 \%)$.

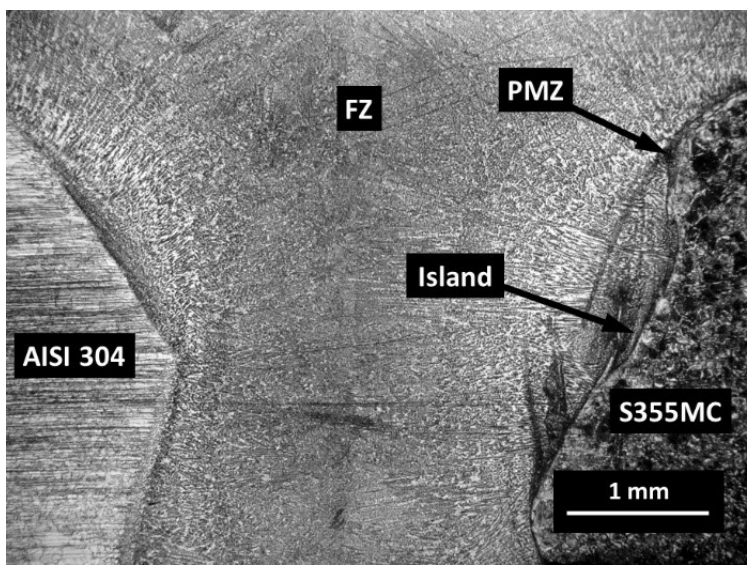

(a)

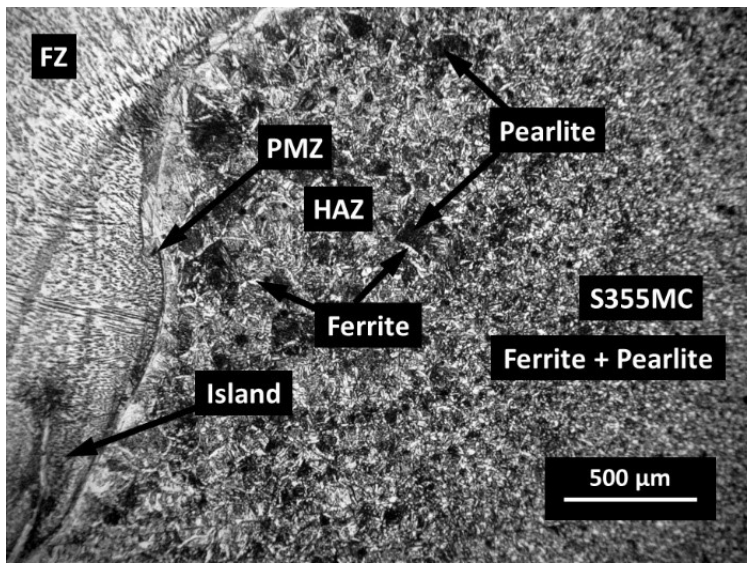

(c)

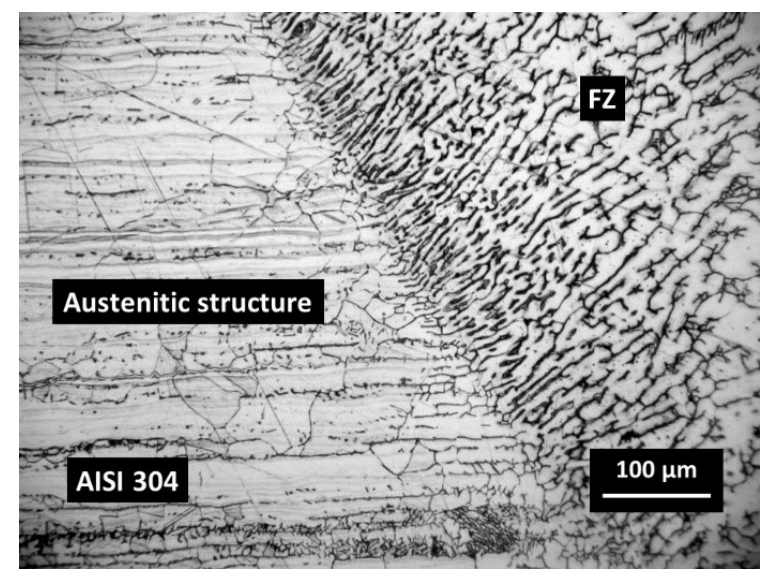

(b)

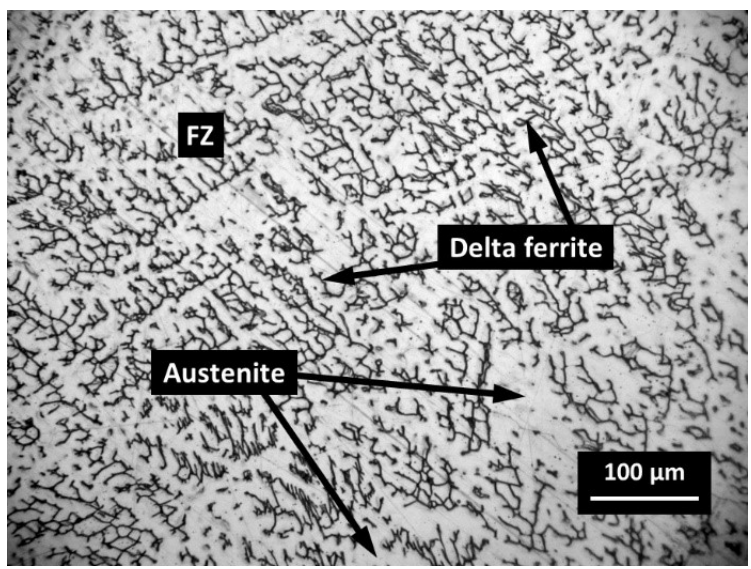

(d)

Figure 6. Optical images of different zones of welded sample AISI 304/S355MC: (a) General view; (b) Partially melted zone AISI 304/FZ; (c) Partially melted zone FZ/S355MC; (d) Delta ferrite and austenite in FZ. 


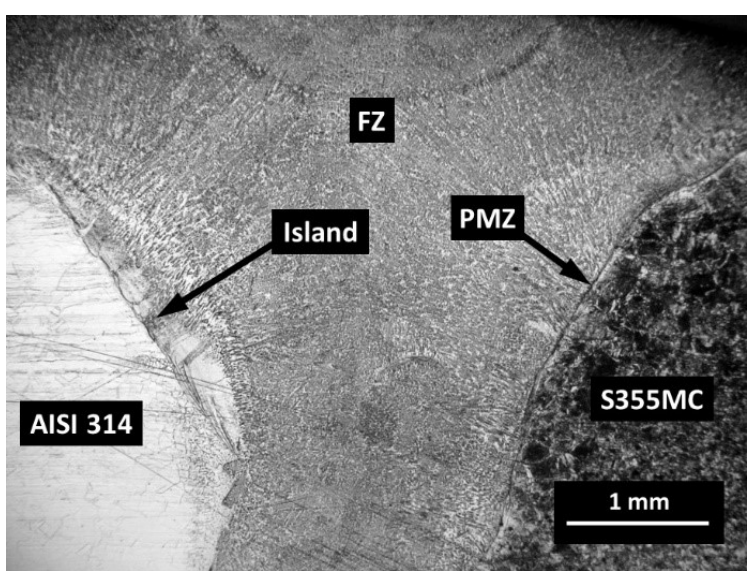

(a)

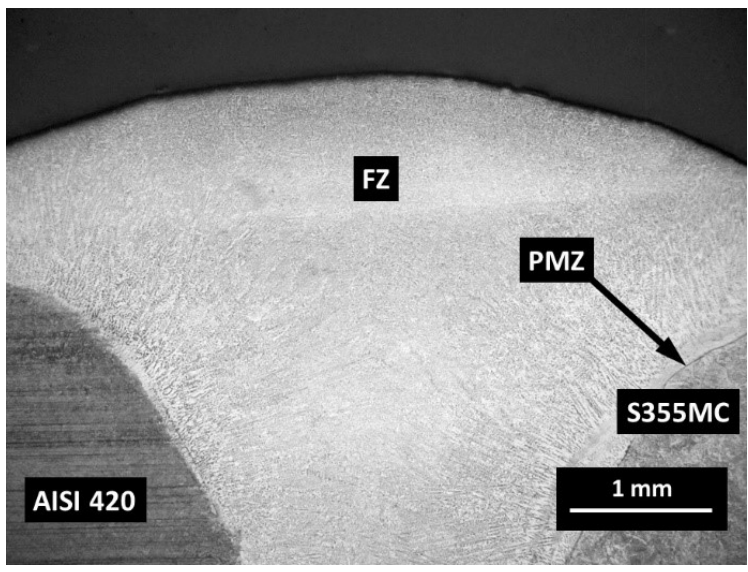

(c)

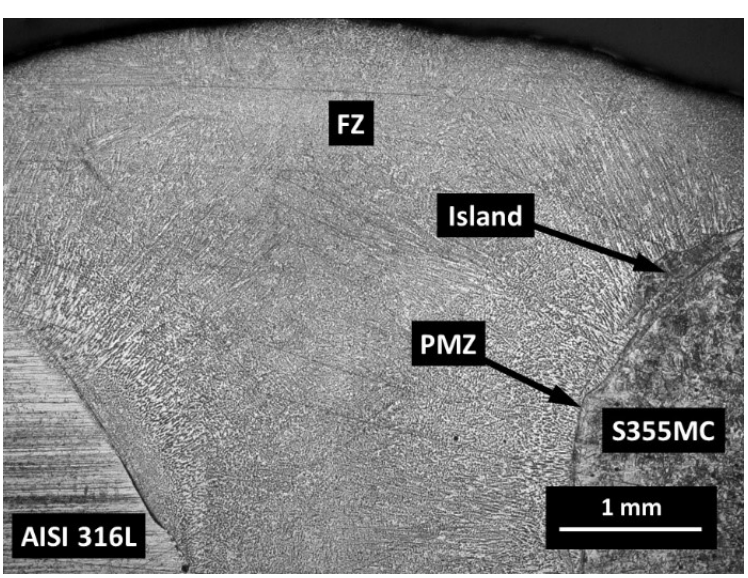

(b)

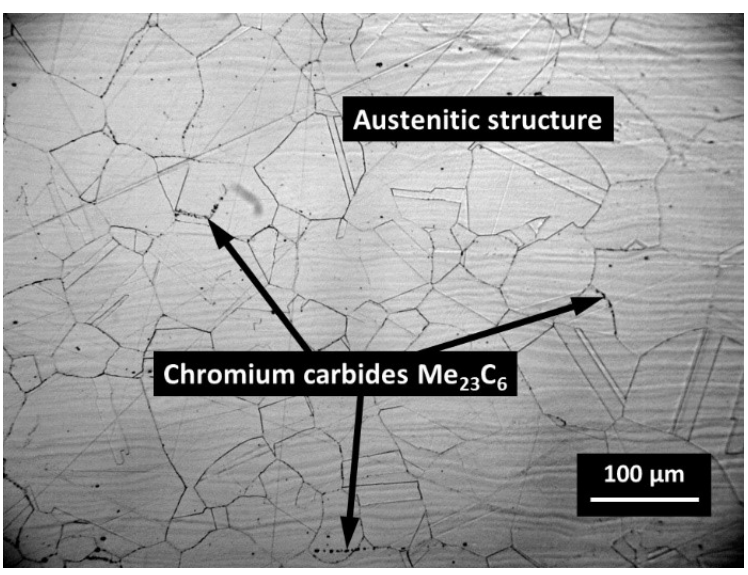

(d)

Figure 7. Optical images of dissimilar welds: (a) AISI 314/S355MC; (b) AISI 316L/S355MC; (c) AISI 420/S355MC; (d) Austenite grains in AISI 314.

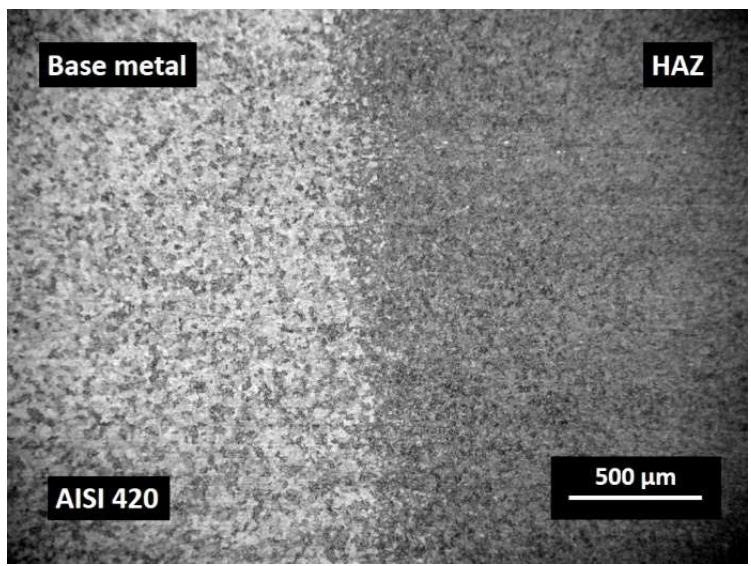

(a)

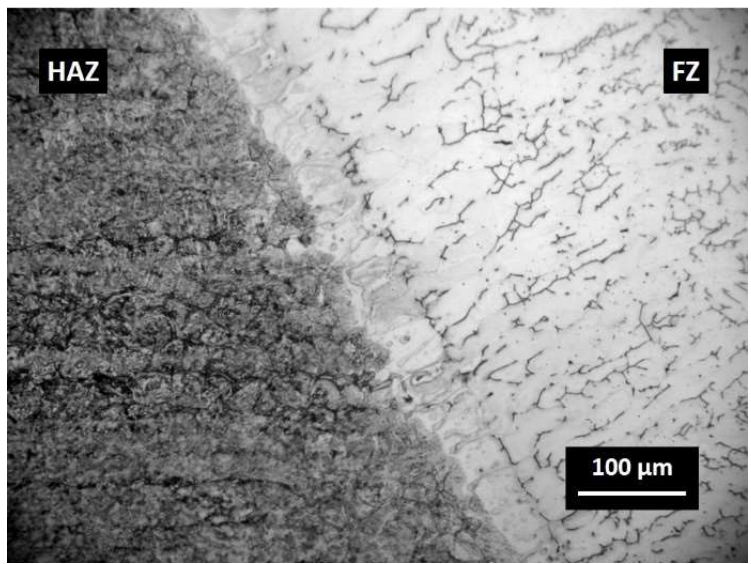

(b)

Figure 8. Optical images of AISI 420: (a) HAZ with coarse untempered martensite (on right) and free tempered martensite in base metal (on left); (b) Partially melted zone AISI 420/FZ.

Examination of micrographs of dissimilar joints did not show the presence of weld defects such as porosity or cracks. 


\subsection{Mechanical tests}

The hardness and tensile tests were accomplished to evaluate mechanical properties of the dissimilar welds.

The hardness profile across the weld joints interface is presented in Figure 9. The hardness of the stainless steels indicated on the left side and hardness of steel S355MC on the right side. Apart from the peaks noticeable in the PMZ of the steel S355MC ( 300 $\mathrm{HV} / 0.1)$, no significant change in hardness was recorded in the stainless steels AISI 304, 314, and 316L except for the joint AISI 420 with S355MC ( $500 \mathrm{HV} / 0.1)$ (Figure 9).

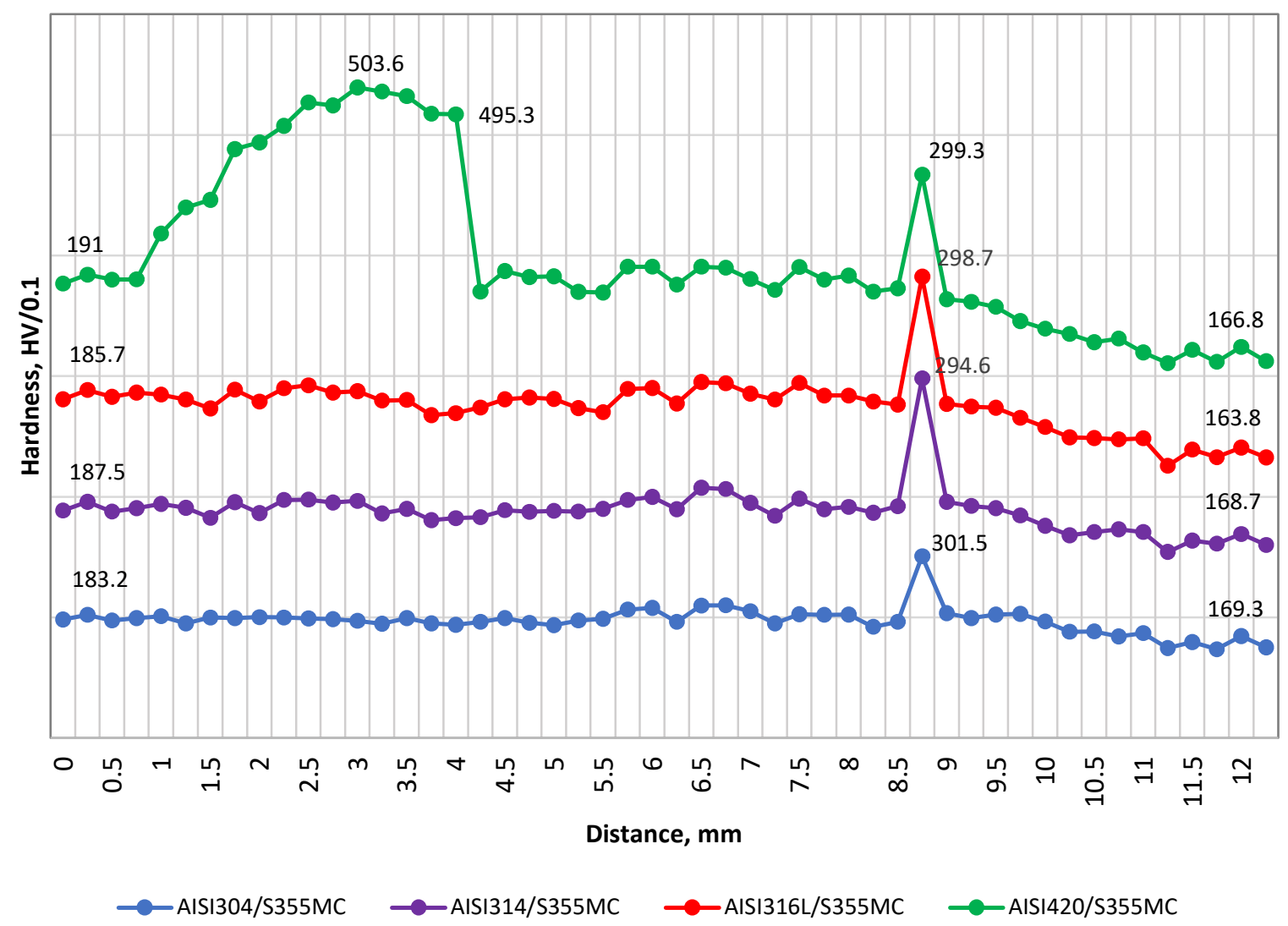

Figure 9. Hardness profile across the weld joints.

The PMZ and HAZ areas of S355MC steel, during the welding process affected by the temperature of austenitization, are completely re-austenitized and then may subsequently transform to sorbite-troostite when slowly cooling until the room temperature. A slower diffusion at lower temperatures results in a formation of finer, harder and stronger structure. In the PMZ area with a temperature of approximately $550{ }^{\circ} \mathrm{C}$, the thickness of ferrite-cementite plates is just approximately $0.1 \mu \mathrm{m}$, and a structure known as troostite having hardness of about $300 \mathrm{HV} / 0.1$ was formed. Decreasing temperature influences the average reduction in austenite grain size with the accompanying decrease in hardenability. Thus, it can be stated that the hardness profile across the PMZ basically shows a peak of hardness at the FZ boundary with a gradually decrease across the coarse grained HAZ. The peaks of the hardness with the width up to $50 \mu \mathrm{m}$ were observed in the PMZ of steel S355MC to FZ boundary and in the islands (Figure 6a,c and Figure 7a-b). Figure 10 presents the image of the weld with the hardness test indentations that size clearly indicates the hardness. Shallow indentation on the island and PMZ indicates a higher hardness of 
these areas compared to the hardness of the FZ and HAZ of the base metal (299 HV/0.1 via $168 \mathrm{HV} / 0.1)$.

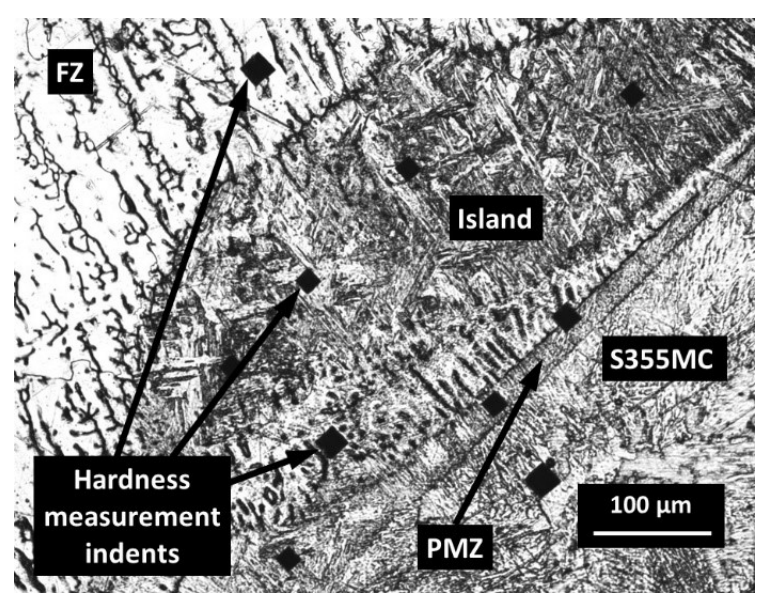

Figure 10. Microstructure of FZ/S355MC with the hardness test's indentations.

The significant increase in hardness of the stainless steel AISI $420 \mathrm{HAZ}$ area (Figure 9) can be explained by the presence of fine untempered martensite that having a structure of small cementite particles in fine grained ferritic matrix negatively affect the ductility [25]. Figure 8 shows the micrographs of the weld metal and HAZ resulting after the welding process: HAZ contained coarse untempered martensite which was hard ( 500 HV/0.1) and relatively brittle compared with the base metal, where hardness values dropped to $\sim 190 \mathrm{HV} / 0.1$, because the tempered martensite at first causes a decrease in hardness. The difference in hardness of HAZ and unaffected BM was $62 \%$.

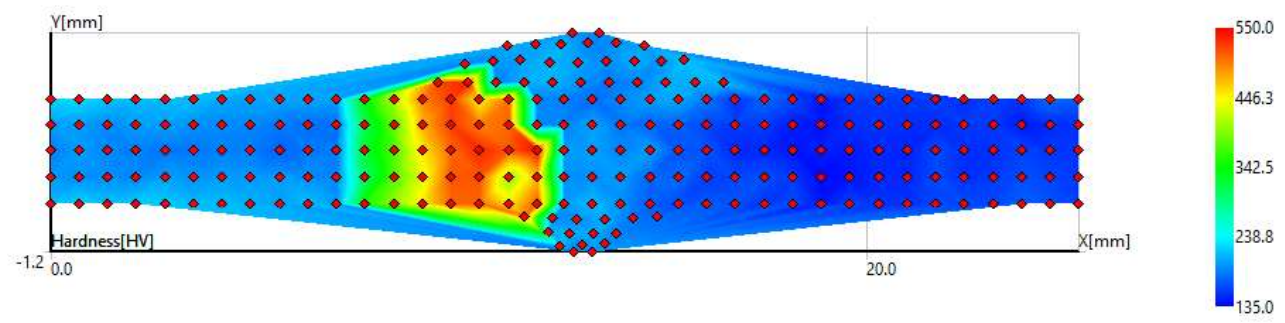

Figure 11. The map of hardness indentations of AISI 420/S355MC dissimilar weld.

The map of hardness showing the distribution of hardness values throughout the surface of the dissimilar weld AISI 420/S355MC is presented in Figure 11. This map allows to quantify the material properties along the length of microstructurally significant weld zones [26]. The employed hardness mapping enabled accurately identify the different welding zones of dissimilar welds and to present clear results in all boundary zones. Colors indicate the zones with similar hardness values of the weld joint. The increase in hardness in the whole HAZ of AISI 420 was caused by the grain size reduction of martensite. Within a relatively short distance from the HAZ, the weld hardness rapidly passes to the base metal hardness level.

The martensite was formed when HAZ close to FZ was heated above the transformation temperature during welding. Usually, unwanted martensite is considered negative and its formation indicates inadequate welding procedures. The coarse untempered martensite was observed in HAZ (Figure 12), while the formation of fine martensitic microstructure was revealed in the BM as it is presented in Figure 8a. Moreover, as the temperature decreases at a distance from HAZ, the carbon diffusion decreases as well as coarsening of precipitation. 


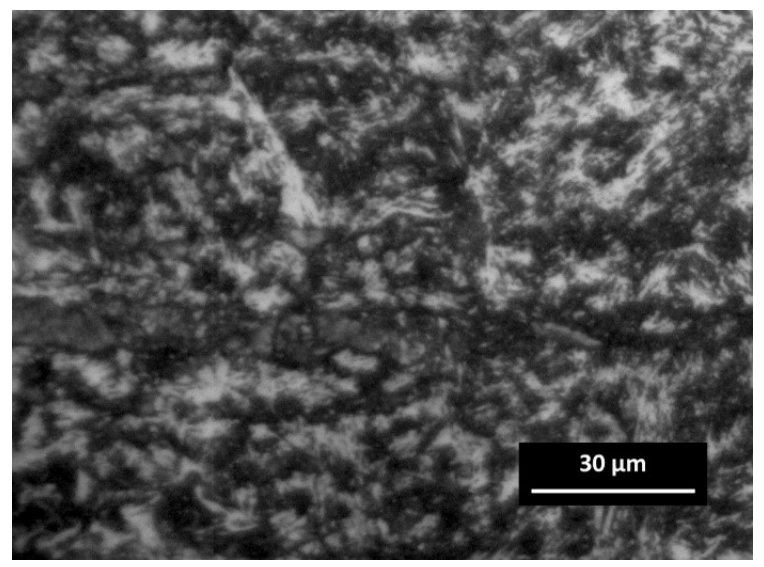

Figure 12. Optical image of untempered martensite in the HAZ of AISI 420.

Saturation of the martensitic base with certain amount of carbon and nitrogen can also cause the increase of hardness in this area: the hardness values ranges from 200 to 505 $\mathrm{HV} / 0.1$. It has been reported, that martensitic structure of high hardness generally has low fracture toughness and are considered as highly susceptible to hydrogen induced cold cracking comparing with structures of lower hardness and higher fracture toughness [27]. The lower hardness level of the BM, compared with that found in the HAZ, is associated and can be explained by the large grain size in the BM.

To assess a suitability of different grades of stainless steels for particular application area and to evaluate the strength of dissimilar welds the tensile tests were carried out. The tensile stress-strain behavior of samples S355MC/AISI 304, 314, 316L and 420 is presented in Figure 13.

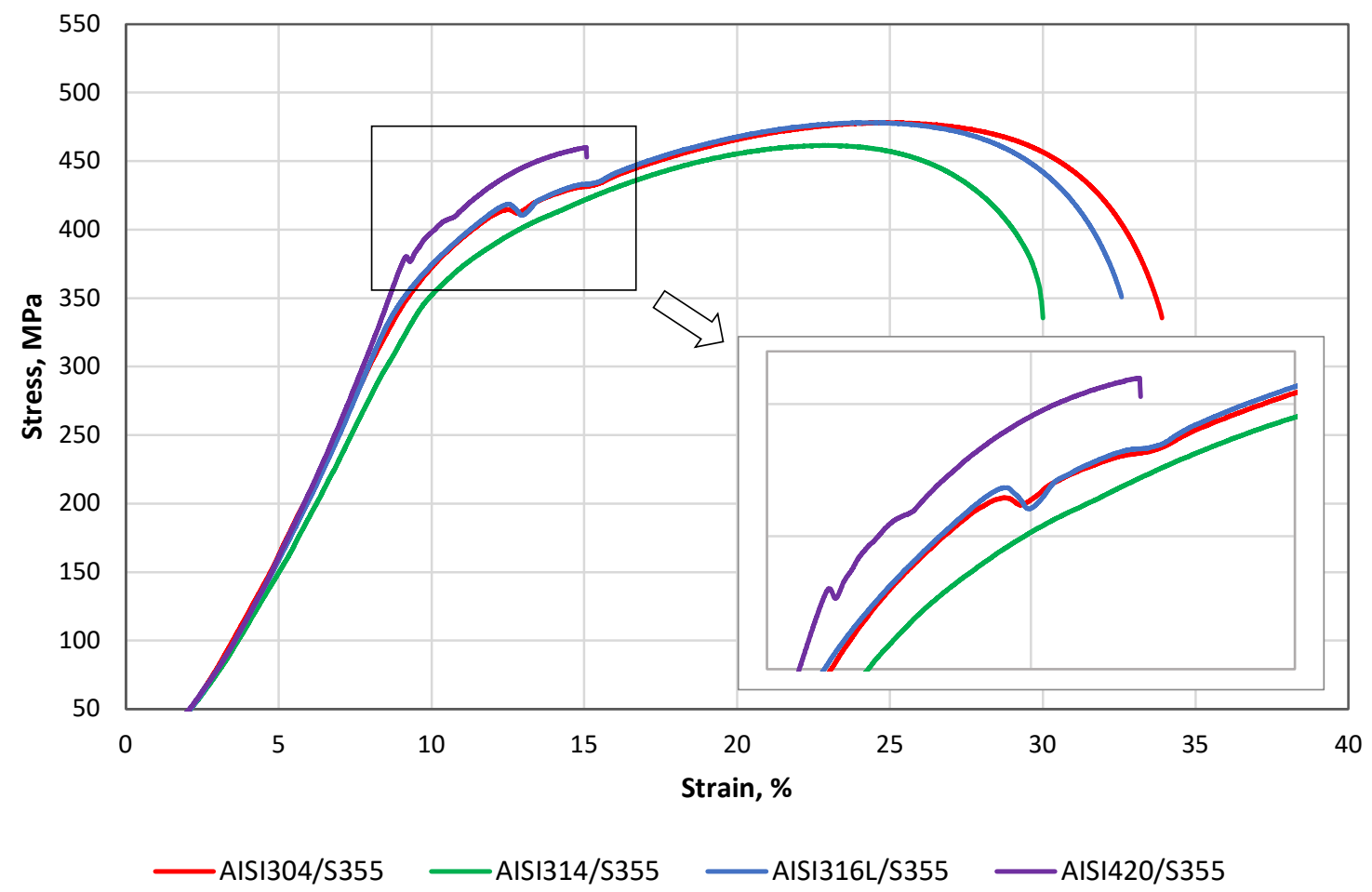

Figure 13. Stress-strain diagrams of dissimilar welds. 
The tensile tests revealed the values of the tensile strength of the dissimilar welds, as can be seen in Figure 13 the values of AISI 304 and AISI 316L are very closely distributed ( $477.7 \pm 2.5$ and $478.0 \pm 2.5$ respectively), the tensile strength of AISI 314 and AISI 420 are slightly lower $(461.4 \pm 2.5$, and $459.8 \pm 2.5 \mathrm{MPa}$, respectively). Tensile tests of all austenitic stainless steels and structural steel S355MC dissimilar weld confirm the acceptable joint strength. The lower strength of AISI 420/S355MC leads to the fracture at a significantly lower relative elongation compared to the other three weldments. Figure 13 clearly shows that the sample AISI 420/S355MC failed the tensile test. This behavior is explained by the mechanical properties of HAZ of AISI 420 weld side, in particular ultimate tensile strength and yield strength, as well as by hardness tests' results. Since the hardness of HAZ area of AISI 420 is higher than the hardness of HAZ area of S355MC and of both base metals (Figure 9), the ductility parameters of the HAZ area of AISI 420 are significantly lower than those of the HAZ area of S355MC and both BMs' due to increased hardness, brittleness and higher carbon content.

It can be clearly seen in Figure 14a, that all cases of the dissimilar austenitic stainless steels AISI 304, 314, 316L and structural steel S355MC welds fracture occurred in the base metal S355MC that met the safety requirements for the dissimilar welds, however, when welding martensitic stainless steel AISI 420 and S355MC, fracture occurred through the weld seam. All the samples of AISI 420 and S355MC dissimilar welds failed at the weld area without any significant necking (Figure 14b). The fracture in AISI 420 occurred between PMZ and BM weld zone from the AISI 420 part. The tensile tests showed lower tensile strength of these samples compared with AISI 304, 314, 316L and S355 dissimilar welds.

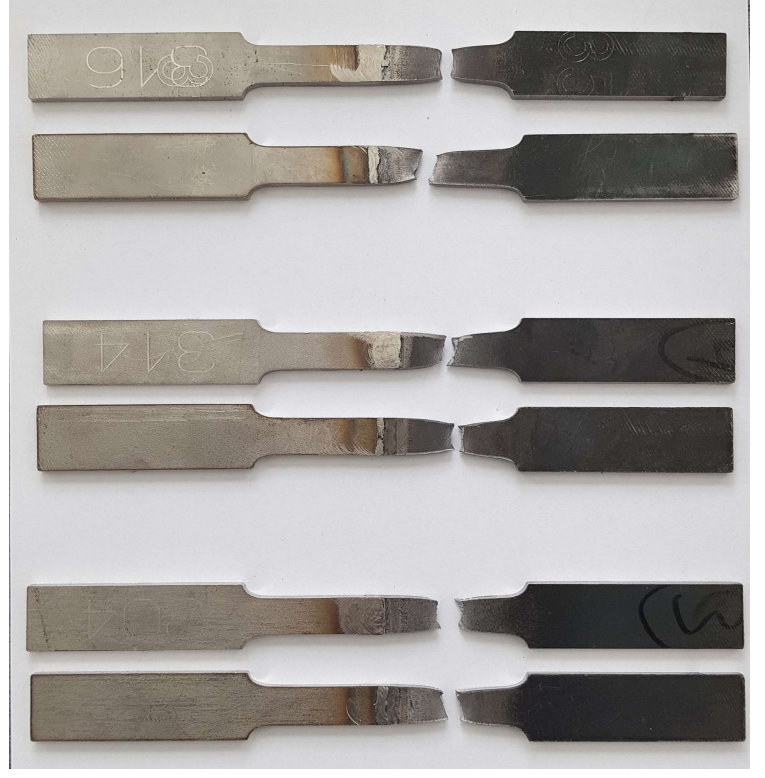

(a)

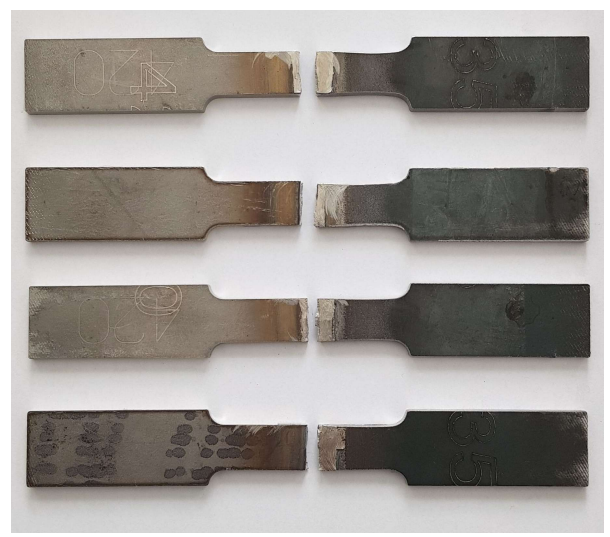

(b)

Figure 14. The fracture positions on tensile samples: (a) Austenitic stainless steels/S355MC; (b) Martensitic stainless steel/S355MC.

None of the tested samples of AISI 420 possessed fracture in the BM and in the FZ. The location of the fracture can also be explained by the fact that the higher strength is associated with the higher strength of untempered martensite, and this area is closer to the FZ. (Figure 8). According to classification of crackings in weldments [28] there is a possible defect No.4 (Figure 15) which forms at the outer edge of the fine grained HAZ close to BM in the over-tempered region. 


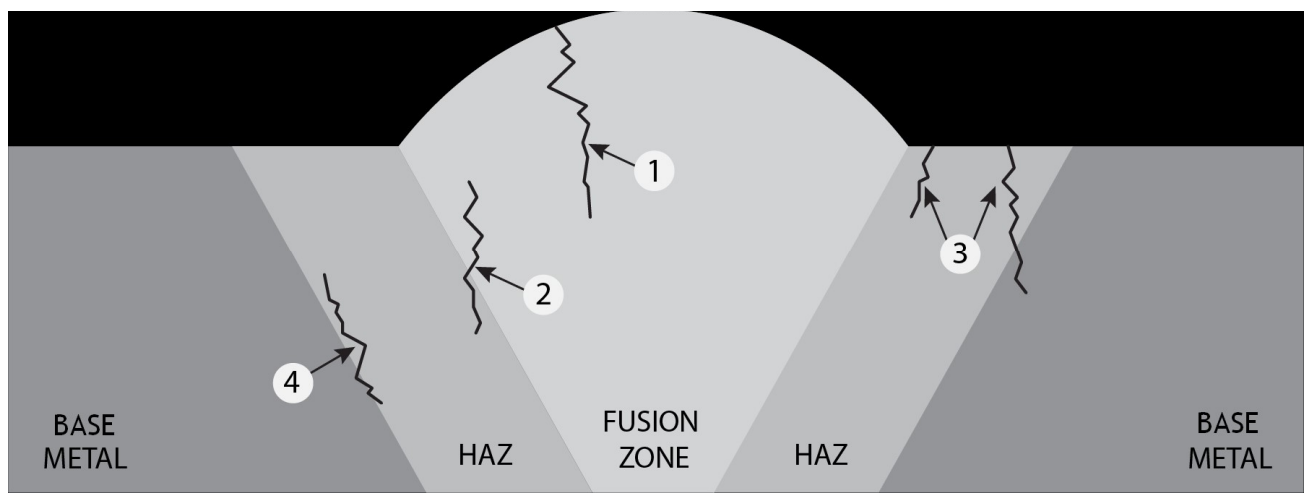

Figure 12. Optical image of untempered martensite in the HAZ of AISI 420.

This type of cracking forms because of HAZ and weld differences in the carbon activity, which is concerned with different concentration of $\mathrm{Cr}$ [28]. The mechanism of cracking No. 4 is typical for welded steels with a chromium content of 9 to 14 percent [29], in case of AISI $420-13.68 \%$ (Table 1 ).

Moreover, the grain size in the weld area is different from that of the base metal. This difference in grain sizes leads to the different yield stresses in such the way decreasing the strength (Hall-Petch relationship [30]). The creep like mechanism manages the fracture in this zone. Obviously, the formation of this mechanism, which is limited specifically to the fined grained regions have to be avoided.

\section{Conclusions}

Summarizing research results achieved after experimental tests, it could be concluded as follows:

- $\quad$ The experimental study proved assumption that MIG welding using the filler rod 308LSi is suitable for dissimilar welds of austenitic stainless and structural high strength low alloy steels, however inappropriate for martensitic stainless and structural high-strength low-alloy steel welds.

- $\quad$ The results of tensile test showed that fracture in all austenitic stainless and structural high-strength low-alloy steels occurred far from the fusion zone in the base metal except the martensitic stainless and structural high strength low alloy steel dissimilar weld case, where the fracture was observed in the heat affected zone. The strength of the weld was approximately determined by the hardness of the fracture site.

- $\quad$ The hardness profiles of dissimilar welds of AISI 304, 314, 316L and S355MC showed very similar tendency with slightly higher hardness of the stainless steel base $\sim 185$ $\mathrm{HV} / 0.1$ than of the structural steel base $\sim 167 \mathrm{HV} / 0.1$, and the same behavior in the partially melted zone of S355MC where hardness increases up to $298 \mathrm{HV} / 0.1$. Similar results were achieved while executing tensile tests: the same geometry of stress-strain diagrams with $472 \mathrm{MPa}$ tensile strength on average.

- $\quad$ The higher value of hardness of the martensitic phase in the HAZ of AISI 420 ( 500 $\mathrm{HV} / 0.1$ ) is influenced by several factors: the higher carbon content and the grain size as well as the presence of untempered martensite. The lower tensile strength $459.8 \pm 2.5 \mathrm{MPa}$ was achieved because of disparity in grain sizes that greatly affect the reduction in strength. The fracture in the weld seam zone occurred from the martensitic stainless steel part. The predominantly untempered martensitic structure resulted in low ductility, hard and brittle HAZ area that fractured before necking with a negligible elongation.

- The FZ metal microstructure of all weld samples consisted of delta ferrite and relatively low presence of retained austenite. In respect to slow cooling, even the low carbon content can cause the formation of chromium carbides $\mathrm{Me}_{23} \mathrm{C}_{6}$ at the grain boundaries. It appears from the fact that HAZ microstructure consists of coarsened 
$\mathrm{M}_{23} \mathrm{C}_{6}$ carbide precipitation as the predominant carbide. Due to the decrease of the temperature at a distance far away from HAZ, coarsening of precipitation decreases.

\begin{abstract}
Author Contributions: Conceptualization, S.B. and A.C.; methodology, R.B.; software, J.B.; validation, S.B., J.B., R.B. and A.C.; formal analysis, K.D.; investigation, K.D.; resources, S.B. and K.D.; data curation, A.C.; writing - original draft preparation, S.B.; writing-review and editing, R.B.; visualization, A.C.; supervision, J.B.; project administration, R.B.; funding acquisition, S.B. All authors have read and agreed to the published version of the manuscript.
\end{abstract}

Funding: This research received no external funding.

Institutional Review Board Statement: Not applicable.

Informed Consent Statement: Not applicable.

Data Availability Statement: Data sharing not applicable.

Conflicts of Interest: The authors declare no conflict of interest.

\title{
References
}

1. Lippold, J.C.; Kotecki, D.J. Welding Metallurgy and Weldability of Stainless Steels; John Wiley \& Sons, Inc.: New Jersey, USA, 2005, p. 376; ISBN 978-0-471-47379-4.

2. Singh, D.K.; Sharma, V.; Basu, R.; Eskandari, M. Understanding the effect of weld parameters on the microstructures and mechanical properties in dissimilar steel welds. Procedia Manuf. 2019, 35, 986-991, doi:https://doi.org/10.1016/j.promfg.2019.06.046.

3. Wang, J.; Lu, M.; Zhang, L.; Chang, W.; Xu, L.; Hu, L. Effect of welding process on the microstructure and properties of dissimilar weld joints between low alloy steel and duplex stainless steel. Int. J. Miner. Metall. Mater. 2012, 19, 518-524, doi:10.1007/s12613-012-0589-z.

4. Kah, P.; Shrestha, M.; Martikainen, J. Trends in Joining Dissimilar Metals by Welding. Appl. Mech. Mater. 2013, 440, 269-276, doi:10.4028/www.scientific.net/AMM.440.269.

5. Pandey, C.; Mahapatra, M.M.; Kumar, P. Effect of post weld heat treatments on fracture frontier and type IV cracking nature of the crept P91 welded sample. Mater. Sci. Eng. A 2018, 731, 249-265, doi:https://doi.org/10.1016/j.msea.2018.06.038.

6. Thakare, J.G.; Pandey, C.; Mahapatra, M.M.; Mulik, R.S. An assessment for mechanical and microstructure behavior of dissimilar material welded joint between nuclear grade martensitic P91 and austenitic SS304 L steel. J. Manuf. Process. 2019, 48, 249-259, doi:https://doi.org/10.1016/j.jmapro.2019.10.002.

7. Paventhan, R.; Lakshminarayanan, P.R.; Balasubramanian, V. Fatigue behaviour of friction welded medium carbon steel and austenitic stainless steel dissimilar joints. Mater. Des. 2011, 32, 1888-1894, doi:https://doi.org/10.1016/j.matdes.2010.12.011.

8. Bettahar, K.; Bouabdallah, M.; Badji, R.; Gaceb, M.; Kahloun, C.; Bacroix, B. Microstructure and mechanical behavior in dissimilar 13Cr/2205 stainless steel welded pipes. Mater. Des. 2015, 85, 221-229, doi:https://doi.org/10.1016/j.matdes.2015.07.017.

9. Ul-Hamid, A.; Tawancy, H.M.; Abbas, N.M. Failure of weld joints between carbon steel pipe and 304 stainless steel elbows. Eng. Fail. Anal. 2005, 12, 181-191, doi:https://doi.org/10.1016/j.engfailanal.2004.07.003.

10. Rowe, M.D.; Nelson, T.W.; Lippold, J.C. Hydrogen-Induced Cracking Along the Fusion Boundary of Dissimilar Metal Welds. Weld. J. 1999, 78, 31-s-37-s.

11. Wang, S.; Ma, Q.; Li, Y. Characterization of microstructure, mechanical properties and corrosion resistance of dissimilar welded joint between 2205 duplex stainless steel and 16MnR. Mater. Des. 2011, 32, 831-837, doi:10.1016/j.matdes.2010.07.012.

12. Baghjari, S.H.; Akbari Mousavi, S.A.A. Effects of pulsed Nd: YAG laser welding parameters and subsequent post-weld heat treatment on microstructure and hardness of AISI 420 stainless steel. Mater. Des. 2013, 43, 1-9, doi:10.1016/j.matdes.2012.06.027.

13. Samih, Y.; Marcos, G.; Stein, N.; Allain, N.; Fleury, E.; Dong, C.; Grosdidier, T. Microstructure modifications and associated hardness and corrosion improvements in the AISI 420 martensitic stainless steel treated by high current pulsed electron beam (HCPEB). Surf. Coatings Technol. 2014, 259, 737-745, doi:https://doi.org/10.1016/j.surfcoat.2014.09.065.

14. Baskutis, S.; Baskutiene, J.; Bendikiene, R.; Ciuplys, A. Effect of weld parameters on mechanical properties and tensile behavior of tungsten inert gas welded AW6082-T6 aluminium alloy. J. Mech. Sci. Technol. 2019, 33, 765-772, doi:10.1007/s12206-019-01316.

15. Eghlimi, A.; Shamanian, M.; Eskandarian, M.; Zabolian, A.; Nezakat, M.; Szpunar, J.A. Evaluation of microstructure and texture across the welded interface of super duplex stainless steel and high strength low alloy steel. Surf. Coatings Technol. 2015, 264, 150-162, doi:https://doi.org/10.1016/j.surfcoat.2014.12.060.

16. Pan, C.; Zhang, Z. Morphologies of the transition region in dissimilar austenitic-ferritic welds. Mater. Charact. 1996, 36, 5-10, doi:10.1016/1044-5803(95)00249-9.

17. Pouraliakbar, H.; Hamedi, M.; Kokabi, A.H.; Nazari, A. Designing of CK45 carbon steel and aisi 304 stainless steel dissimilar welds. Mater. Res. 2014, 17, 106-114, doi:10.1590/S1516-14392013005000170.

18. Lippold, J.C. Welding metallurgy and weldability; John Wiley \& Sons, Inc.: New Jersey, USA, 2015, p. 400; ISBN 978-1-118-230701. 
19. Xi, W.; Jiao, Z.; Hao, K. Research on Mechanism of Internal Cracking of Welds Caused by Carbon Migration of Welding Joints. In Proceedings of the IOP Conference Series: Earth and Environmental Science; 2019; Volume 252.

20. You, Y.-Y.; Shiue, R.-K.; Shiue, R.-H.; Chen, C. The study of carbon migration in dissimilar welding of the modified 9Cr-1Mo steel. J. Mater. Sci. Lett. 2001, 20, 1429-1432, doi:10.1023/A:1011616232396.

21. Kaneko, K.; Fukunaga, T.; Yamada, K.; Nakada, N.; Kikuchi, M.; Saghi, Z.; Barnard, J.S.; Midgley, P.A. Formation of M23C6type precipitates and chromium-depleted zones in austenite stainless steel. Scr. Mater. 2011, 65, 509-512, doi:10.1016/j.scriptamat.2011.06.010.

22. Loder, D.; Michelic, S.; Bernhard, C. Acicular Ferrite Formation and Its Influencing Factors - A Review. J. Mater. Sci. Res. 2017, 6, 24-43, doi:http://dx.doi.org/10.5539/jmsr.v6n1p24.

23. Capdevila, C.; Caballero, F.G.; De Andrés, C.G. Austenite grain size effects on isothermal allotriomorphic ferrite formation in 0.37C-1.45Mn-0.11V microalloyed steel. Mater. Trans. 2003, 44, 1087-1095, doi:10.2320/matertrans.44.1087.

24. Folkhard, E. Welding Metallurgy of Stainless Steels; Springer-Verlag Vienna: Vienna, Austria, 1988, p. 279; ISBN 978-3-7091-89672.

25. Krauss, G. Martensite before and after Tempering, Deformation and Fracture of. In; Buschow, K.H.J., Cahn, R.W., Flemings, M.C., Ilschner, B., Kramer, E.J., Mahajan, S., Veyssière, P.B.T.-E. of M.S. and T., (Eds.) Elsevier: Oxford, UK, 2001; pp. 5193-5197 ISBN 978-0-08-043152-9.

26. Brayshaw, W.J.; Roy, M.J.; Sun, T.; Akrivos, V.; Sherry, A.H. Iterative mesh-based hardness mapping. Sci. Technol. Weld. Join. 2017, 22, 404-411, doi:10.1080/13621718.2016.1251713.

27. Dunne, D.P.; Pang, W. Displaced hardness peak phenomenon in heat-affected zone of welded quenched and tempered EM812 steel. Weld. World 2017, 61, 57-67, doi:10.1007/s40194-016-0385-x.

28. Abson, D.J.; Rothwell, J.S. Review of type IV cracking of weldments in 9- $12 \% \mathrm{Cr}$ creep strength enhanced ferritic steels. Int. Mater. Rev. 2013, 58, 437-473, doi:10.1179/1743280412Y.0000000016.

29. Creep-Resistant Steels; Abe, F.; Kern, T.-U.; Viswanathan, R., (Eds.) 1st Edition; Woodhead Publishing Limited: Cambridge, UK, 2008, p. 700; ISBN 978-1-84569-178-3.

Failure mechanisms of advanced welding processes; Sun, X., (Ed.) 1st Edition; Woodhead Publishing Limited: Cambridge, UK, 2010, p. 336; ISBN 9781845695361. 